\title{
POLÍTICA, CONSTITUIÇÃO E JUSTIÇA: OS DESAFIOS PARA A CONSOLIDAÇÃO DAS INSTITUIÇÕES DEMOCRÁTICAS ${ }^{1}$
}

\author{
Anderson Orestes Cavalcante Lobato \\ Universidade do Vale do Rio dos Sinos \\ Universidade de Caxias do Sul
}

\begin{abstract}
RESUMO
Os atores politicos encontram na Constituição os contornos institucionais para uma política democrática. Contudo, o texto constitucional não seria capaz de oferecer as condições necessárias à estabilidade governamental. A concretização de uma política de governo exigirá a reforma da Constituição, bem como uma jurisprudência constitucional uniforme; a Justiça Constitucional encontra-se, desse modo, no centro do debate político democrático. A tensão existente entre a vontade política do Governo e a vontade da Constituição somente poderia ser equilibrada pelo Judiciário, cuja instituição estaria vivenciando uma crise de legitimidade, organização e procedimento.
\end{abstract}

PALAVRAS-CHAVE: constitucionalidade; democracia; justiça constitucional; reforma do Judiciário; judicialização da política.

\section{INTRODUÇÃO}

Os temas "política" e "Direito" estão intimamente relacionados. O ponto de contato seria a percepção do fenômeno do poder. Numa perspectiva relacional, o poder seria a possibilidade de impor a alguém a adoção de um determinado comportamento; numa perspectiva institucional o poder designaria a oposição entre Estado e cidadão. Para Georges Burdeau, "o poder é uma força a serviço de uma idéia” (BURDEAU, 1970, p. 25); uma idéia de Direito que pertence ao grupo social, organizado na forma de uma instituição, o Estado. Desse modo, o Direito procura condicionar a atuação do poder político quando fixa, na Constituição do Estado, os limites para o seu exercício. É ainda Burdeau quem sintetiza: "A Constituição é o estatuto jurídico do poder” (idem, p. 75).

1 Este trabalho foi originalmente apresentado na mesaredonda Consolidação da democracia: enfoques teóricos e processos político-institucionais, realizada durante o Seminário Internacional de Ciência Política: Política desde el Sur, entre 3 e 5 de outubro de 2001 na Universidade Federal do Rio Grande do Sul (UFRGS). O evento foi organizado com o patrocínio do Departamento de Ciência Política da UFRGS, do seu Programa de Pós-Graduação em Ciência Política e da Associação das Universidades do Grupo de Montevidéu.
Poder e Constituição estão em permanente contato. De fato, a definição de uma política de governo pode encontrar no texto constitucional um limite cuja superação dependeria de uma reforma da Constituição. Contudo, a rigidez constitucional impõe ao Governo a busca de um consenso nem sempre possível de obter em face da conjuntura político-partidária. A engenharia constitucional pode determinar as condições para um relacionamento democrático entre poder e Constituição, haja vista que a rigidez constitucional não pode ser de tal ordem que inviabilize a condução de uma política de governo. Porém, a política de governo não pode depender exclusivamente da reforma constitucional, pois o governo deve agir no sentido da realização das expectativas da cidadania, expressa diretamente na Constituição, pelo exercício do poder constituinte originário. Assim sendo, o poder constituinte derivado, que admite a reforma do texto constitucional, é excepcional e destina-se a oferecer uma possibilidade permanente de atualização da Constituição. A política de governo deve, portanto, estar em conformidade com o texto constitucional; a vontade da Constituição deve prevalecer e a eventual reforma constitucional teria o objetivo de corrigir as imperfeições de um processo democrático de deliberação. 
A consolidação da democracia brasileira encontraria no debate entre política e Direito um momento delicado de avaliação da continuidade das instituições democráticas. Com efeito, uma autonomia maior na condução da política de governo poderia representar um enfraquecimento das instituições democráticas constitucionalmente definidas. Por outro lado, uma imposição do texto constitucional tal como aprovado em 1988 poderia representar uma incapacidade do Estado constitucional em adaptar-se às novas condições sociais e políticas, identificadas na política de governo.

Enfim, a tensão entre política e Direito suscita uma reflexão sobre Justiça. A sua institucionalização no poder Judiciário conquistou legitimidade pela adoção de um modo especial de organização e procedimento. Na explicação de Montesquieu, o poder Judiciário seria, de qualquer modo, nulo. A função jurisdicional estaria afastada do debate entre política e Direito, posto que a solução jurídica, neutra e imparcial, não poderia questionar nem a decisão política, nem o Direito, cujo ponto de contato seria a edição da lei. Ao Judiciário caberia tão-somente a aplicação cega e imparcial da lei. Com a sua edição, o debate entre política e Direito estaria encerrado, e doravante a questão passaria a ser estritamente jurídica. A correta aplicação da lei, seria definida pelo debate quanto à sua interpretação e relação com o caso concreto, sub judice.

Entretanto, o Estado democrático de Direito atribui ao poder Judiciário a importante função de guardião da Constituição, portanto da idéia de Direito que animou a formação do próprio Estado constitucional. Na defesa do texto constitucional o Judiciário está efetivamente contribuindo para a consolidação, ou melhor para o fortalecimento das instituições democráticas; torna-se transparente a sua atuação no controle de constitucionalidade, o que tem suscitado o debate sobre a judicialização da política.

\section{O FORTALECIMENTO DAS INSTITUI- ÇÕES DEMOCRÁTICAS}

As instituições democráticas no Brasil encontram-se em fase de consolidação. De fato, a transição democrática permitiu a adoção de uma Constituição que, contando com uma forte legitimidade popular, encontra no debate entre política e Direito o desafio para a concretização das expectativas inseridas no novo texto consti- tucional. Assim é que o Executivo procura governar através da edição de leis que sejam fruto de um espaço democrático de decisão. Contudo, a interpretação da Constituição brasileira de 1988, ao permitir uma ampla atividade legislativa do Executivo através da reedição de medidas provisórias, termina desequilibrando a relação entre os poderes do Estado, admitindo pois uma hipertrofia do Executivo $(a)$. Porém a Constituição impõe limites ao poder político $(b)$, que poderão ser fiscalizados através da atuação do poder Judiciário.

\section{a) a hipertrofia do poder Executivo}

As instituições democráticas devem estar protegidas pelo princípio da separação dos poderes; contudo, o regime político determina o relacionamento entre esses poderes. Assim, no regime parlamentar percebe-se a necessidade de colaboração entre os poderes, posto que o PrimeiroMinistro, chefe do governo, deve contar com a confiança do Parlamento, o poder Legislativo. A racionalização do regime parlamentar permitiu a adoção de instrumentos constitucionais de reequilíbrio do relacionamento entre Executivo e Legislativo, tais como a moção de censura e a dissolução da Assembléia. A relação de confiança que se estabelece conduz à afirmação de uma separação flexível dos poderes. De fato, a governabilidade estará assegurada diretamente pela relação de confiança quando a direção do Executivo e do Legislativo pertence ao mesmo partido político ou aliança; ou através dos instrumentos constitucionais de equilíbrio, nos períodos de coabitação de forças políticas adversas.

No regime presidencial o relacionamento entre os poderes será de independência e equilíbrio. Nesse sentido, identificamos instrumentos constitucionais de controle e bloqueio da atuação governamental, em que o veto presidencial e a necessidade de conversão em lei da atividade legislativa excepcional do Executivo seriam representativos. É certo que Executivo e Legislativo procuram negociar politicamente a condução de uma política de governo, notadamente no momento de composição dos postos de ministros da República. Contudo, no presidencialismo brasileiro, como de fato vem ocorrendo nas democracias latino-americanas (SARTORI, 1996, p. 109), a necessidade de negociação foi diminuída, posto que a possibilidade de reedição das medidas provisórias dispensou o Executivo de buscar um consenso no Legislativo para obter a 
sua conversão em lei. Os números são particularmente reveladores. No Quadro I observase claramente como, na Nova República, o Executivo foi servindo-se da medida provisória para impor a sua política de governo. Pode-se afirmar pois que o grande número de reedições representaria uma resistência do Legislativo à política governamental.

QUADRO I - Evolução das edições e reedições de Medidas Provisórias

\begin{tabular}{|l|c|c|}
\hline \multicolumn{1}{|c|}{ Presidente da República } & Originais & Reedições \\
\hline José Sarney (mar.1988-mar.1990) & 125 & 22 \\
\hline Fernando Collor (mar.1990-out.1992) & 89 & 70 \\
\hline Itamar Franco (out.1992-dez.1994) & 142 & 363 \\
\hline Fernando H. Cardoso (jan.1995-dez.1998) & 160 & 2449 \\
\hline Fernando H. Cardoso (jan.1999-set.2001) & 103 & 2587 \\
\hline
\end{tabular}

Fonte: BRASIL. Presidência da República (2001).

A falta de diálogo entre governo e oposição pode conduzir a uma situação de ruptura institucional, posto que o regime democrático pressupõe a busca de consenso como uma garantia de respeito à vontade do cidadão. Na medida em que o governo não necessita dialogar com a oposição para pôr em prática a sua política governamental, quebra-se o espaço democrático de tomada da decisão política e o risco de opressão reaparece, não restando ao cidadão outra alternativa que não a resistência-inicialmente através das manifestações públicas de repúdio a uma política governamental que se distancia, claramente, das expectativas populares, podendo inclusive chegar à ruptura com o Estado constitucional que fôra incapaz de assegurar uma política governamental democrática.

Nessa perspectiva, a Constituição brasileira enfrenta o desafio de efetivamente impor limites ao exercício do poder político, obrigando, por um lado, um diálogo entre governo e oposição, mas, por outro lado, assegurando que as expectativas da cidadania venham a ser concretizadas. A esperança na realização das promessas constitucionais de emancipação social e econômica do brasileiro excluído é que pode assegurar o fortalecimento das instituições democráticas, que dependem pois dos instrumentos constitucionais de limitação do poder.

\section{b) os limites constitucionais ao exercício do poder político}

A engenharia constitucional deve pois assegurar o bom relacionamento entre os poderes do Estado. A vocação primeira do Estado constitucional é a de poder impor limites ao exercício do poder político. O princípio da separação dos poderes procura reduzir o risco de tirania obrigando constitucionalmente a busca de um consenso entre Executivo e Legislativo na condução de uma política de governo. Espera-se que a democracia e a vontade soberana do cidadão possam ser desse modo observada, posto que os governantes gozam de uma legitimidade conquistada através de eleições periódicas, pelo sufrágio universal, livre, direto e secreto.

A aprovação da Emenda Constitucional n. 32, em setembro último, procurou conter o abuso do Executivo na utilização das medidas provisórias através de dois recursos básicos: por um lado, vedando a sua utilização em matérias que possam comprometer a independência dos poderes e diminuir os direitos de cidadania; por outro, proibindo claramente a sua reedição, que doravante será admitida uma única vez, sendo que a sua nãovotação poderá bloquear a atividade das casas legislativas.

Nessa perspectiva, a Emenda Constitucional procurou restabelecer o equilíbrio entre os poderes Executivo e Legislativo, que fôra quebrado pela possibilidade de reedição indiscriminada das medidas provisórias, levando o governo a um isolamento, que, embora se pudesse fazer sentir, a interpretação dada ao texto constitucional não fôra capaz de corrigir, caracterizando assim uma hipertrofia do Executivo que estava no limite de comprometer a consolidação da democracia brasileira.

Interessante perceber que diante do fenômeno da hipertrofia do Executivo, a oposição encontrou no Poder Judiciário um órgão de soberania do Estado capaz de bloquear e corrigir uma política governamental que procurou impor-se, abandonando o diálogo democrático. A judicialização da política seria pois uma resposta à falta de consenso 
no debate político. O Judiciário é chamado a posicionar-se sobre uma questão política sempre que a lei não conseguiu alcançar um grau de consenso satisfatório. Nesse momento, a Constituição ressurge como norma parâmetro para a aceitação e legitimidade do programa de governo e resgata-se, assim, a sua força normativa através do processo constitucional de controle de constitucionalidade das leis e das ações constitucionais de proteção dos direitos fundamentais.

\section{A JUDICIALIZAÇÃO DA POLÍTICA}

No Estado democrático a decisão política deve ser o resultado de um amplo debate entre governo e oposição. No presidencialismo brasileiro, contudo, o jogo político tende a uma relação do tudo ou nada, ou seja, o governo procura impor a sua política, procurando esquivar-se do debate democrático entre os poderes do Estado. Numa tal conjuntura não resta à oposição e à sociedade civil organizada outra alternativa senão se socorrer no poder Judiciário, na esperança de resistir a uma política governamental imposta unilateralmente. $\mathrm{O}$ poder Judiciário assume assim a tarefa de árbitro do debate democrático encontrando na Constituição o parâmetro para as suas decisões. As questões políticas, não resolvidas pelo debate democrático, serão trazidas ao poder Judiciário através do controle da constitucionalidade das leis e das ações de constitucionais de proteção dos direitos fundamentais.

Nesse sentido, o Brasil admite a judicialização da política desde a primeira constituição republicana de 1891, de inspiração norte-americana. De fato, desde então o poder Judiciário brasileiro exerce o controle da constitucionalidade das leis e dos atos da administração pública, bem como a defesa dos Direitos fundamentais através da ação constitucional de habeas corpus. Porém, o grau de engajamento do Judiciário depende diretamente de um espaço democrático, de modo que, nos períodos de constitucionalismo autoritário, o controle de constitucionalidade e a proteção dos Direitos de cidadania tornam-se tímidos e excessivamente formalistas. A redemocratização do país permitiu a redescoberta da Constituição e da jurisdição constitucional.

A judicialização da política não é pois exclusiva à democracia brasileira. Trata-se de um fenômeno conhecido das democracias consolidadas e o fato de o Brasil enfrentar tal problemática sinaliza a consolidação de nossas instituições democráticas.
Com efeito, a denominada jurisdição constitucional representa a institucionalização de um espaço de controle da atuação do governo de modo a evitar as arbitrariedades cometidas pelas maiorias eventuais. A oposição, bem como os movimentos minoritários, encontra na jurisdição constitucional um árbitro que deve ter como única preocupação o respeito aos valores sociais - a idéia de Direito que se consolida no texto constitucional.

A atual conjuntura brasileira tem demonstrado que a relação entre política, Constituição e Justiça que se estabelece no contencioso constitucional, encontra dificuldades institucionais para adaptarse aos novos tempos. Assim, o sistema concreto e difuso de controle de constitucionalidade de inspiração norte-americana encontra sérios desajustes que podem comprometer severamente o seu exercício $(a)$. Por outro lado, a necessidade de firmar-se uma jurisprudência constitucional $(b)$ não vem sendo compreendida, posto que suscita o sério receio de bloqueio da atuação judicial em face de uma interpretação imposta pelo seu órgão de cúpula, o Supremo Tribunal Federal.

\section{a) Os desajustes do controle concreto e difuso da constitucionalidade das leis}

O fenômeno da judicialização da política manifesta-se primeiramente no controle de constitucionalidade concreto e difuso. De fato, todo cidadão jurisdicionado, ou seja, que procura o poder Judiciário para obter uma solução justa ao seu conflito de interesses, tem o direito de pedir a nãoaplicação de uma lei que esteja contrariando frontalmente o texto constitucional. Assim sendo, todo Juiz ou Tribunal poderá decidir a questão de inconstitucionalidade suscitada no curso de um processo judicial encontrando uma solução justa para o litígio que, em concreto, poderá deixar de aplicar uma lei, total ou parcialmente, declarando a sua inconstitucionalidade.

Desse modo, os atos Legislativos do governo sofrem um efetivo controle jurisdicional da sua constitucionalidade. Um tal controle teria o condão de obrigar os governantes a observar as aspirações da cidadania expressas diretamente na Constituição. Trata-se efetivamente de um fortalecimento das instituições democráticas, posto que o cidadão tem a possibilidade efetiva e concreta de corrigir a atuação de uma política de governo que se afasta do espírito da Constituição e, portanto, do cidadão.

Entretanto, a dificuldade desse sistema de 
controle de constitucionalidade estaria no seu desajuste em relação ao modelo jurídico romanista adotado no Brasil. De fato, nesse contexto as leis criam o Direito e uma lei, ainda que inconstitucional, pode produzir efeitos jurídicos concretos que poderão não ser corrigidos pelo poder Judiciário, posto que cada juiz é livre e independente para interpretar o texto constitucional e o caso concreto, de modo a aceitar ou não a questão de inconstitucionalidade. Por outro lado, uma decisão pela inconstitucionalidade produz efeitos jurídicos limitados às partes no processo, passíveis de recurso. Assim, a decisão definitiva sobre a inconstitucionalidade de uma lei somente ocorrerá, in concreto, após a declaração de inconstitucionalidade pronunciada pelo Supremo Tribunal Federal, em Recurso Extraordinário, o que pode demorar cerca de dez anos, diante dos problemas de morosidade da justiça brasileira.

A preocupação com o aumento do contencioso constitucional perante o Supremo Tribunal Federal não é de fato uma novidade trazida pela Constituição de 1988. Os números apresentados nos Quadros II e III demonstram contudo que as tentativas de aclimatação (TAVARES, 1986) do controle concreto e difuso à realidade constitucional brasileira até o momento não se fizeram sentir.

QUADRO II - A evolução dos Processos no Supremo Tribunal Federal

\begin{tabular}{|c|c|c|c|c|c|c|c|}
\hline Ano & 1940 & 1950 & 1960 & 1970 & 1980 & 1990 & 2000 \\
\hline Recebidos & 2419 & 3091 & 6504 & 6367 & 9555 & 18564 & 105307 \\
\hline Julgados & 1807 & 3371 & 5747 & 6486 & 9007 & 16449 & 86138 \\
\hline
\end{tabular}

Fonte: BRASIL. Supremo Tribunal Federal (2001).

Observa-se claramente que nos períodos do constitucionalismo autoritário de 1940 a 1950 e de 1960 a 1980 a evolução processual permaneceu estável, chegando mesmo a diminuir de 1960 a 1970. O salto aconteceu com o processo de transição democrática, iniciado em 1985. Intensificouse no período de 1980 a 1990, quando o Supremo Tribunal teve que administrar uma demanda que simplesmente dobrou em dez anos. Contudo, o período de 1990 a 2000 aponta para o perigo de estagnação, pois a judicialização multiplicou-se por cinco em dez anos. A preocupação em conter o aumento de processos concentra-se pois nos Recursos Extraordinários e nos Agravos, quando as partes são obrigadas a dar continuidade ao contencioso constitucional concreto para obter uma decisão definitiva do Supremo Tribunal Federal.

QUADRO III - Percentagem de Recursos Extraordinários e Agravos em relação ao total de processos distribuídos no STF

\begin{tabular}{|c|c|c|c|c|}
\hline Ano & $\begin{array}{c}\text { Total de processos } \\
\text { distribuídos }\end{array}$ & $\begin{array}{c}\text { Recursos extraordinários } \\
\text { distribuídos }\end{array}$ & Agravos distribuídos & $\begin{array}{c}\text { Relacão RE-AG/processos } \\
\text { distribuídos (\%) }\end{array}$ \\
\hline 1990 & 16226 & 10780 & 2465 & 81,6 \\
\hline 1991 & 17567 & 10518 & 5380 & 90,5 \\
\hline 1992 & 26325 & 16874 & 7838 & 93,9 \\
\hline 1993 & 23525 & 12281 & 9345 & 91,9 \\
\hline 1994 & 25868 & 14984 & 8699 & 91,6 \\
\hline 1995 & 25385 & 11195 & 11803 & 90,6 \\
\hline 1996 & 23883 & 9265 & 12303 & 90,3 \\
\hline 1997 & 34289 & 14841 & 16863 & 92,5 \\
\hline 1998 & 50273 & 20595 & 26168 & 93,0 \\
\hline 1999 & 54437 & 22280 & 29677 & 95,4 \\
\hline 2000 & 90839 & 29196 & 59236 & 97,4 \\
\hline
\end{tabular}

Fonte: BRASIL. Supremo Tribunal Federal (2001).

Ora, os números apresentados no Quadro III justificam sobremaneira a preocupação do Tri- bunal. No último ano o controle concreto representou $97,4 \%$ da demanda judicial. É certo que 
muitos desses processos são semelhantes e a decisão será sem sombra de dúvida idêntica em todos eles. A questão passaria a ser simplesmente administrativa, posto que juridicamente a posição do Tribunal já fôra firmada. No entanto, a segurança jurídica e a efetividade da Justiça estarão comprometidas. Ora, se o Supremo Tribunal recebe esse grande número de processos pela via do controle concreto e difuso da constitucionalidade, é sem dúvida em razão da resistência dos juízes e tribunais estaduais que firmaram, por seu turno, uma jurisprudência divergente. O jurisdicionado vê-se pois na obrigação de seguir no processo até a última e definitiva instância para ver confirmada a posição do Tribunal Supremo.

As duas tentativas de contenção do gradual aumento de Recursos Extraordinários, abrindose a possibilidade de intervenção do Senado Federal e a obrigatoriedade de pronunciamento da declaração de inconstitucionalidade pela maioria absoluta do órgão especial ou plenário dos tribunais, não surtiram os efeitos desejados. O constituinte de 1987-88 procurou aproximar a experiência brasileira de controle judicial da constitucionalidade à experiência européia da jurisdição constitucional abstrata e concentrada. Fortaleceram-se assim as ações constitucionais, que, dirigidas diretamente ao Supremo Tribunal Federal, poderiam encerrar uma controvérsia constitucional com força obrigatória geral, formando-se uma jurisprudência constitucional coerente e uniforme.

b) O resgate de uma jurisprudência constitucional

As ações constitucionais do controle abstrato das normas no Direito constitucional brasileiro estão divididas em quatro situações distintas: (a)
Ação Direta de Inconstitucionalidade; (b) Ação Declaratória de Constitucionalidade; (c) Ação de Inconstitucionalidade por Omissão, e (d) Ação de Argüição de Descumprimento de Preceito Fundamental.

No controle abstrato a questão de inconstitucionalidade é apreciada independentemente de um caso concreto. Desse modo, a sua decisão produzirá efeitos erga omnes, vinculando todos as autoridades públicas, inclusive os órgãos do Judiciário. A questão de inconstitucionalidade é assim resolvida uma única vez, evitando-se pois a multiplicação de processos idênticos perante o Supremo Tribunal Federal, a sobrecarregar o tribunal e evitando também, nas instâncias inferiores, decisões divergentes em razão de uma interpretação difusa.

Não se trata pois de eliminar o controle concreto e difuso, mas sim de oferecer-lhe uma racionalidade que possa fortalecer suas decisões em matéria de controle de constitucionalidade. Evitase, igualmente, a adoção de uma súmula vinculante, essa sim incompatível tanto com o sistema jurídico romanista quanto com o princípio democrático de elaboração das normas jurídicas, posto que os tribunais superiores terminariam por criar normas jurídicas que estariam à margem do processo democrático (princípio da separação dos poderes) e acima da Constituição (na medida em que ofereceria uma interpretação constitucional sem possibilidade de controle político).

Interessante observar que, apesar da adoção do controle abstrato, o número de recursos extraordinários não recuou, mas o número de ações de inconstitucionalidade não cessa de crescer, como fica demonstrado no Quadro V abaixo.

QUADRO V - Evolução das Ações de Inconstitucionalidade no Supremo Tribunal Federal

\begin{tabular}{|c|c|c|c|c|c|c|}
\hline \multirow{2}{*}{ Ano } & \multicolumn{2}{|c|}{ ADIN } & \multicolumn{2}{c|}{ ADECON } & \multicolumn{2}{c|}{ ADPF } \\
\cline { 2 - 7 } & Distribuídas & Julgadas & Distribuídas & Julgadas & Distribuídas & Julgadas \\
\hline 1990 & 267 & 85 & - & - & - & - \\
\hline 1991 & 232 & 72 & - & - & - & - \\
\hline 1992 & 166 & 99 & - & - & - & - \\
\hline 1993 & 159 & 124 & 1 & 1 & - & - \\
\hline 1994 & 196 & 94 & - & - & - & - \\
\hline 1995 & 207 & 128 & - & - & - & - \\
\hline 1996 & 158 & 135 & - & - & - & - \\
\hline 1997 & 203 & 143 & 3 & 2 & - & - \\
\hline 1998 & 182 & 151 & 2 & 1 & - & - \\
\hline
\end{tabular}




\begin{tabular}{|l|l|l|l|l|l|l|}
\hline 1999 & 185 & 117 & 2 & 2 & - & - \\
\hline 2000 & 257 & 96 & - & - & 10 & 3 \\
\hline
\end{tabular}

Fonte: BRASIL. Supremo Tribunal Federal (2001).

É certo que no final de 1999 foi editada a Lei n. 9868 , regulamentando o processo do controle abstrato, confirmando, em grande parte, a posição adotada pela jurisprudência do próprio Supremo Tribunal Federal. A adoção, no mesmo ano, da Lei n. 9 882, regulamentando o processo da Argüição de Descumprimento de Preceito Fundamental, terminou por admitir mais uma espécie de controle abstrato das normas, assumindo a particularidade de procurar conjugar as duas modalidades de controle abstrato e concreto.

A otimização encontra-se claramente proposta no momento da concessão da medida liminar na Ação Declaratória de Constitucionalidade (Art. 21, Lei n. 9 868/99) e na Argüição de Descumprimento de Preceito Fundamental (Art. 5º Lei n. 9 882/ 99). Nesses dois casos a concessão da medida liminar, com o objetivo de preservar os direitos dos jurisdicionados, tem o condão de suspender todos os processos judiciais que estejam tratando do mesmo objeto. Nesse sentido, julgado a questão de inconstitucionalidade pela via do controle abstrato, a sua decisão, com força obrigatória geral, resolveria todos os demais processos, firmando assim uma jurisprudência forte e coerente.

A vantagem do controle abstrato em relação à prolatada súmula vinculante estaria no fato de que a jurisdição constitucional exige uma fundamentação jurídica (Art. 93, IX, Constituição Federal de 1988) que no tempo contribuiria para o fortalecimento da Constituição, na medida em que encontraria no poder Judiciário um aliado na defesa dos direitos de cidadania.

\section{CONCLUSÃO}

A jurisdição constitucional provoca uma institucionalização do relacionamento entre política, Constituição e Justiça. Propõe de fato uma releitura do princípio da separação dos poderes em que a tese clássica de Montesquieu, sem perder o sentido de limitação do poder político através de instrumentos de controle entre poderes, seria fortalecida pela participação do poder Judiciário na defesa das instituições democráticas e dos direitos de cidadania. A decisão de Justiça sobre questões políticas não-resolvidas pelo consenso entre governantes ou entre esses e a cidadania encontraria na judicialização uma possibilidade de fiscalização da política de governo tendo como norma-parâmetro a Constituição.

Os governantes devem pois aceitar que os seus poderes estão limitados pela vontade da Constituição. É certo que receberam através do voto popular um mandato para criar novas regras jurídicas para assim obterem a realização de seus programas de governo; contudo, essas leis somente terão validade na medida em que estejam em conformidade com a Constituição. Não se diga, portanto, que a última palavra sobre a adoção de uma política governamental estaria sendo transferida para o Judiciário, reaparecendo o fantasma do governo dos juízes. Ora, o governante guarda sempre a última palavra, posto que poderá, no limite, reformar o texto constitucional, e assim obter a implementação de sua decisão política. A Constituição exige tão-somente um consenso entre governo e oposição que se expressará no respeito ao processo Legislativo mais complexo e rigoroso para a aprovação de emendas constitucionais.

O fenômeno da judicialização da política segue a evolução natural do Estado de Direito que se democratiza. Com efeito, a decisão judicial, protegida pela fundamentação jurídica e das garantias institucionais e pessoais do julgador, contribui sensivelmente para o fortalecimento das instituições democráticas. A jurisdição constitucional e a democracia caminham lado a lado em busca da realização de idéia de Direito. Essa idéia encontra na Constituição não somente um momento de declaração, programática e sem força jurídica, mas sim uma aspiração de emancipação do cidadão que, participante, procura influenciar a adoção de uma política de governo que tenha na Constituição do Estado as bases de sua ação governamental.

No contexto atual a jurisdição constitucional brasileira vive um momento delicado de estagnação. Por um lado, ocorre que a imposição de uma política de governo pelo presidencialismo aumenta significativamente o grau de litigiosidade perante os tribunais, em particular perante o Supremo Tribunal Federal. Por outro lado, há a incapacidade 
do Judiciário em firmar uma jurisprudência constitucional que possa orientar as decisões da Justiça em todo território nacional. Trata-se sim de uma questão de técnica constitucional que no fundo encobre uma questão política que deve ser enfrentada rapidamente. O Poder Judiciário no constitucionalismo democrático precisa resgatar a sua legitimidade. Essa legitimidade não poderá ser obtida através do processo eleitoral como ocorre com o Executivo e o Legislativo. A legitimidade do Judiciário residiria na sua capacidade de proteger os Direitos do cidadão e sobretudo, de resistir à pressão política exercida pelo governo.

A função da jurisdição constitucional é a de preservar a vontade da Constituição em face das maiorias eventuais que podem violar os Direitos de cidadania. O seu papel assim definido obriga a uma nova engenharia constitucional que conduzirá a uma reforma do Judiciário, primeiramente no modo de organização dos tribunais superiores quem sabe com a adoção de um Tribunal Constitucional. Esse tribunal teria a tarefa de redefinir toda a estrutura do Poder Judiciário brasileiro, inclusive abrindo-se a discussão sobre a admissibilidade de um controle externo, bem como da revisão de procedimentos que, valorizando o formalismo processual, representaram, no passado autoritário, um espaço de resistência, mas que no espaço democrático podem comprometer a força das decisões de Justiça.

Recebido para publicação em 8 de outubro de 2001. Artigo aprovado em 23 de novembro de 2001.

Anderson Orestes Cavalcante Lobato (aoclobato@uol.com.br) é Doutor em Direito Público pela Universidade de Ciências Sociais de Toulouse, França, e Professor do Programa de Pós-Graduação em Direito da Universidade Vale do Rio dos Sinos (Unisinos) e da Universidade de Caxias do Sul (UCS).

\section{REFERÊNCIAS BIBLIOGRÁFICAS}

BRASIL. 1988. Constituição da República Federativa do Brasil. Brasília.

BRASIL. PRESIDÊNCIA DA REPÚBLICA. 2001. www.presidencia.gov.br : novembro.

BRASIL. SUPREMO TRIBUNAL FEDERAL. 2001. www.stf.gov.br : novembro.

BURDEAU, G. 1970. L'État. Paris : Seuil.

CAPPELLETTI, M. 1987. Nécessité et legitimité de la justice constitutionnelle. In : FAVOREU, L. Cours constitutionnelles européennes et droits fondamentaux. Paris : Economica/ PUAM.

GUERRA FILHO, W. S. 2000. Teoria processual da Constituição. São Paulo : Celso Bastos.

LOBATO, A. C. 1994. Para uma nova compreensão do sistema misto de controle de constitucionalidade : a aceitação do controle preventivo. Cadernos de Direito Constitucional e Ciência Política. São Paulo, v. 2, n. 6, p. 35-46, jan.-mar.

1999. A contribuição da jurisdição constitucional para a consolidação do Estado democrático de Direito. In : ROCHA, L. S., STRECK, L. L. \& MORAIS, J. L. B. (orgs.).
Anuário do programa de pós-graduação em Direito. São Leopoldo : Unisinos.

MENDES. G. F. 1995. O poder Executivo e o poder Legislativo no controle de constitucionalidade. Arquivos do Ministério da Justiça, Brasília, v. 48, n. 186, p. 41-90, jul.-dez.

SARTORI, G. 1996. Engenharia constitucional : como mudam as constituições. Brasília : Edunb.

SILVA, J. A. 2000. Poder constituinte e poder popular : estudos sobre a Constituição. São Paulo : Malheiros.

TAVARES, A. L. L. 1986. Aspects de l'acclimatation du judicial review au droit brésilien. Revue Internationale de Droit Comparé, Paris, v. 4, p. 1136-1159.

TROPER, M. \& JAUME, L. (dir.). 1994. 1789 et l'invention de la Constitution. Paris : Bruylant/LGDJ.

TROPER, M. 1994. Pour une théorie juridique de l'État. Paris : PUF.

VIEIRA, O. V. 1999. A Constituição e sua reserva de Justiça : um ensaio sobre os limites materiais ao poder de reforma. São Paulo : Malheiros. 